\title{
Study on Proton Radiation Resistance of 410 Martensitic Stainless Steels under 3 MeV Proton Irradiation
}

\author{
Jae-Woong Lee ${ }^{1}$, S. Surabhi' ${ }^{1}$, Soon-Gil Yoon ${ }^{1}$, Ho Jin Ryu ${ }^{2}$, Byong-Guk Park ${ }^{3}$, \\ Yeon-Ho Cho ${ }^{4}$, Yong-Tae Jang ${ }^{4}$, and Jong-Ryul Jeong ${ }^{1 *}$ \\ ${ }^{I}$ Department of Materials Science and Engineering, Graduate School of Energy Science and Technology, \\ Chungnam National University, Daejeon 34134, Korea \\ ${ }^{2}$ Department of Nuclear and Quantum Engineering, KAIST, Daejeon 34141, Korea \\ ${ }^{3}$ Department of Materials Science and Engineering, KAIST, Daejeon 34141, Korea \\ ${ }^{4}$ Mechanical System Engineering Department, KEPCO E\&C, Daejeon 34057, Korea
}

(Received 16 March 2016, Received in final form 30 March 2016, Accepted 30 March 2016)

\begin{abstract}
In this study, we report on an investigation of proton radiation resistance of $\mathbf{4 1 0}$ martensitic stainless steels under $3 \mathrm{MeV}$ proton with the doses ranging from $1.0 \times 10^{15}$ to $1.0 \times 10^{17} \mathrm{p} / \mathrm{cm}^{2}$ at the temperature $623 \mathrm{~K}$. Vibrating sample magnetometer (VSM) and X-ray diffractometer (XRD) were used to study the variation of magnetic properties and structural damages by virtue of proton irradiation, respectively. VSM and XRD analysis revealed that the $\mathbf{4 1 0}$ martensitic stainless steels showed proton radiation resistance up to $10^{17} \mathrm{p} / \mathrm{cm}^{2}$. Proton energy degradation and flux attenuations in 410 stainless steels as a function of penetration depth were calculated by using Stopping and Range of Ions in Matter (SRIM) code. It suggested that the 410 stainless steels have the radiation resistance up to $5.2 \times 10^{-3}$ dpa which corresponds to neutron irradiation of $3.5 \times 10^{18} \mathrm{n} / \mathrm{cm}^{2}$. These results could be used to predict the maintenance period of SUS410 stainless steels in fission power plants.
\end{abstract}

Keywords : martensitic steels, magnetization, ferromagnet, proton irradiation

\section{Introduction}

Application of magnetic materials in fission power plants can be limited by the problem of finding the relevant materials with sufficient resistance to neutron irradiation [1]. Possessing outstanding magnetic and mechanical properties by virtue of their intrinsic nature, magnetic stainless steels have been generated a lot of interest and evolved as very strong candidate materials in the fission power plants [2-5]. Ferritic and martensitic stainless steels are usually categorized as magnetic stainless steels since they exhibit a high magnetic permeability. Whereas, the austenitic stainless steels are often described as non-magnetic steels as their magnetic permeability is quite negligible [3-5]. Magnetic permeability values for the magnetic steels whose principal metallic phases at room temperature are ferrite and martensite are usually high ( 14), whereas, the non-magnetic steels have a mag-

(C)The Korean Magnetics Society. All rights reserved.

*Corresponding author: Tel: +82-42-821-6633

Fax: +82-42-822-5850, e-mail: jrjeong@cnu.ac.kr netic permeability of 1.0 or slightly more. Austenitic stainless steels fall into this latter category because their austenitic structure at room temperature favors in low magnetic permeability [3-5].

400 stainless steel series are generally martensitic and free from austenite, so they exhibit high permeability and attract a lot of attention in the applications of magnetic devices [2-5]. These series of steels can be magnetized in the low electric field so that they can be used for electric solenoid cores. Among the various 400 series, 410 stainless steels, which are heat treatable alloys with a lower $\mathrm{Cr}$ and higher carbon content, have excellent creep strength and corrosion resistance and are suitable for high-temperature operation [6-8]. Therefore, they become strong candidates for structural, as well as promising magnetic materials for next generation fission power plants. For example, 410 stainless steels attract a lot of attention for potential applications in in-vessel magnetic cores, where good corrosion resistance is required. However, the radiation effects on the magnetic properties of the 410 stainless steels, which are crucial for the application of 410 stainless steels in the in-vessel magnetic cores, are not investi- 
gated well in detail.

In this work, we have investigated the effects of proton irradiation on the magnetic properties of 410 stainless steels in order to understand the correlation between irradiation damage and magnetic property degradation. Proton irradiation was used to simulate neutron irradiation since it imparts same damages as neutron irradiation and also can provide short irradiation time and high damage rate $[9,10]$. And also, the penetration depth and transmutation in proton irradiation is very less $[11,12]$. Temperature dependent magnetic properties were also investigated in order to check the possibility of a hightemperature operation.

\section{Experiments}

The thin 410 stainless steel plates $(\sim 35 \mu \mathrm{m})$ for the proton irradiation were prepared by mechanical polishing and finally polished by diamond suspension to avoid the surface roughness effect on the magnetic properties of the samples. A 3MV pelletron accelerator in Michigan Ion Beam Laboratory (MIBL) system was used for proton irradiation experiments. The ion beam accelerator including the quadrupole focusing unit and the ion beam can be irradiated to cover a uniform area of about $100 \mathrm{~mm}^{2}$. A temperature-variable sample holder was used to maintain the sample temperature at $632 \mathrm{~K}$ during the proton irradiation. The amount of the dose was varied from $1 \times$ $10^{15}$ to $1 \times 10^{17} \mathrm{p} / \mathrm{cm}^{2}$. The magnetic and structural properties of the 410 stainless steels before and after the irradiation have been investigated by using vibrating sample magnetometer (VSM) in the temperature range of 300-700 K and X-ray diffractometry (XRD), respectively.

\section{Results and Discussion}

The penetration depth of proton highly depends on the acceleration energy, thereby the proton energy degradation and flux attenuations of 410 stainless steels as a function of penetration depth was simulated by using Stopping and Range of Ions in Matter (SRIM) program. Figure 1 shows that the penetration depth of proton into the stainless steels was changed from 1.6 to $1820 \mu \mathrm{m}$ by varying proton incident energy $\left(E_{p}\right)$ from $3 \mathrm{keV}$ to 30 $\mathrm{MeV}$ when the fluence was $1 \times 10^{14} \mathrm{p} / \mathrm{cm}^{2}$. Proton radiation damages defined by displacement per atom (dpa) due to exposure of proton was also calculated and plotted in Fig. 1. Contrary to the penetration depth, the average radiation damages were reduced from $4.9 \times 10^{-5}$ to $3.3 \times$ $10^{-6} \mathrm{dpa}$ as $E_{p}$ increased from $3 \mathrm{keV}$ to $30 \mathrm{MeV}$. By considering irradiation time and sample thickness, we

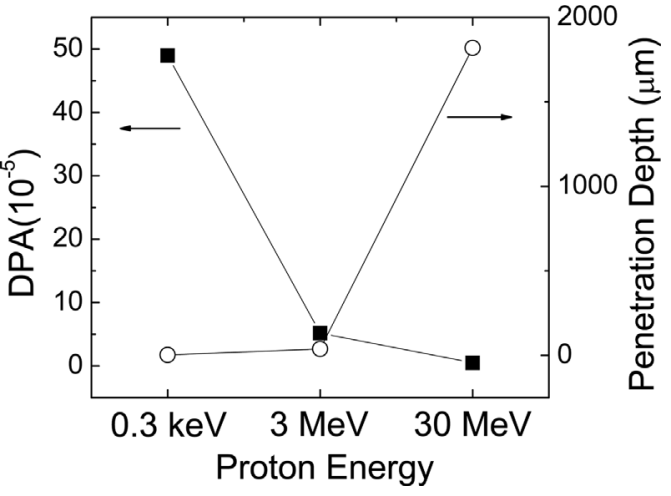

Fig. 1. Proton penetration depth and proton induced damages in dpa for stainless steels calculated by SRIM code.

chose $E_{p}=3 \mathrm{MeV}$ and prepared the samples with the thickness of $\sim 35 \mu \mathrm{m}$ to guarantee proton penetration into the materials. In the proton irradiation experiment, the proton fluence $\left(F_{p}\right)$ was varied from $1 \times 10^{15}$ to $1 \times 10^{17}$ $\mathrm{p} / \mathrm{cm}^{2}$ and sample temperature was fixed to $632 \mathrm{~K}$.

To investigate the effect of proton irradiation on the magnetic properties of martensitic stainless steels, we measured magnetic hysteresis loops by using VSM before and after the irradiation. Figure 2a shows the measured magnetic hysteresis loops by varying $F_{p}$ from $1 \times 10^{15}$ to $1 \times 10^{17} \mathrm{p} / \mathrm{cm}^{2}$. For all samples, the saturation magnetic field is measured around $1,000 \pm 1.5$ Oe and the coercivity was around $17 \pm 1.5$ Oe. The inset shows the

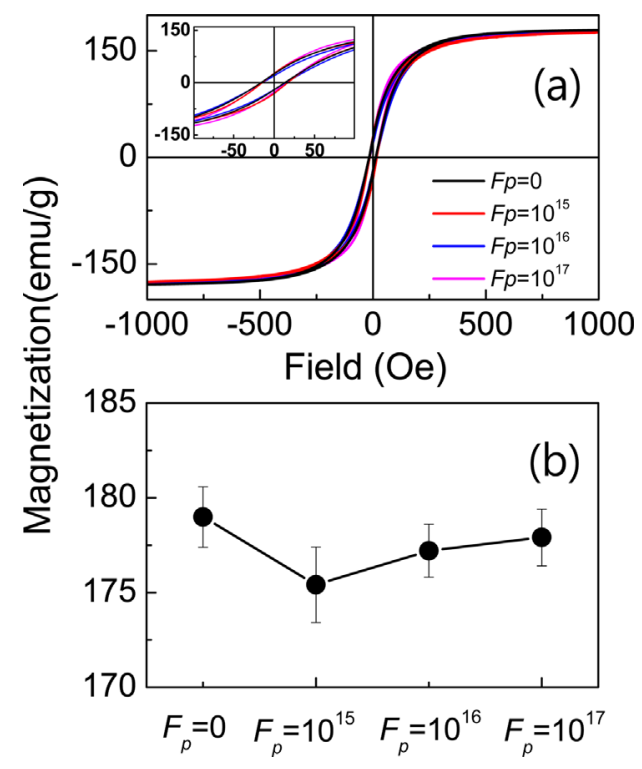

Fig. 2. (Color online) (a) Magnetic hysteresis loops of the stainless steel samples after $3 \mathrm{MeV}$ proton irradiation with the doses ranging from $10^{15}-10^{17} \mathrm{p} / \mathrm{cm}^{2}$ measured at $300 \mathrm{~K}$. (b) Variation of saturation magnetization with respect to proton irradiation. 


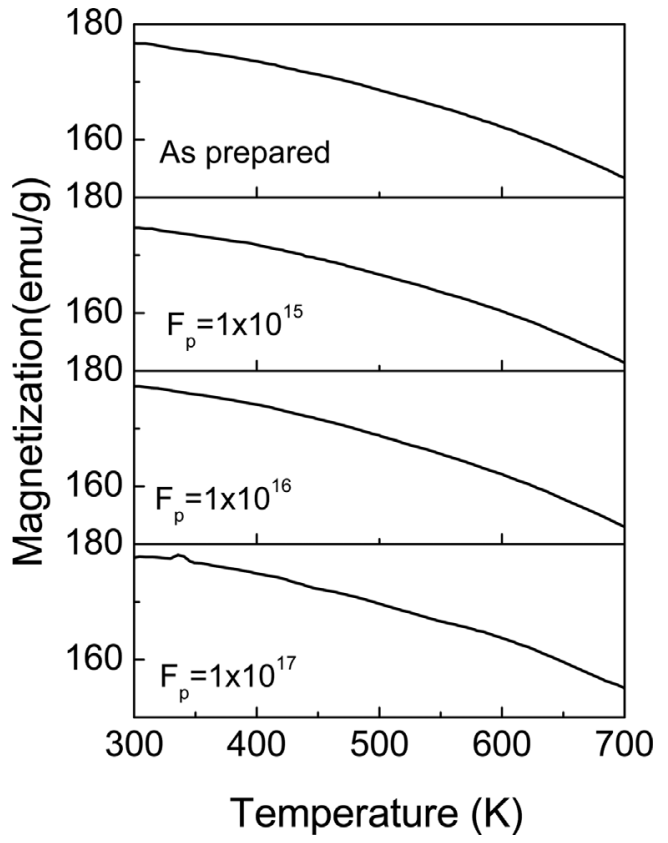

Fig. 3. Magnetization vs. temperature curves of the stainless steel samples after $3 \mathrm{MeV}$ proton irradiation with the doses ranging from $10^{15}-10^{17} \mathrm{p} / \mathrm{cm}^{2}$.

zoom-in plot from -100 Oe to 100 Oe and Fig. 2b shows the variation of saturation magnetization loops by varying $F_{p}$ from $1 \times 10^{15}$ to $1 \times 10^{17} \mathrm{p} / \mathrm{cm}^{2}$. It clearly shows that the magnetic properties of 410 stainless steels were not affected by the proton irradiations up to $10^{17} \mathrm{p} / \mathrm{cm}^{2}$. As shown in Fig. 2, all the hysteresis parameters including the saturation magnetization $\left(M_{\mathrm{s}}\right)$, coercivity, remanent magnetization, and saturation magnetic field were only changed within the experimental errors due to the proton irradiation up to $10^{17} \mathrm{p} / \mathrm{cm}^{2}$.

Temperature dependence of magnetization curves was measured in order to examine the effects of proton irradiation on the high-temperature magnetic properties of the samples. During the measurements, the applied magnetic field was fixed to 1000 Oe. Figure 3 shows the magnetization vs. temperature curves by varying the $F_{p}$ from $1 \times 10^{15}$ to $1 \times 10^{17} \mathrm{p} / \mathrm{cm}^{2}$. A reduction of saturation magnetization and coercivity were observed as compared to room temperature measurements. However, similar to the hysteresis measurements, it also shows that the temperature dependence of magnetic properties of martensitic stainless steels is not significantly affected by proton irradiation. The magnetic hysteresis loops measured at $700 \mathrm{~K}$ by varying $F_{p}$ from $1 \times 10^{15}$ to $1 \times 10^{17} \mathrm{p} / \mathrm{cm}^{2}$ were shown in Fig. 4. Irrespective to the proton irradiation, the saturation magnetization and coercivity were measured around $152 \pm 2.3 \mathrm{emu} / \mathrm{g}$ and $10 \pm 1.5 \mathrm{Oe}$, respectively.

In general, the magnetic properties of magnetic materials

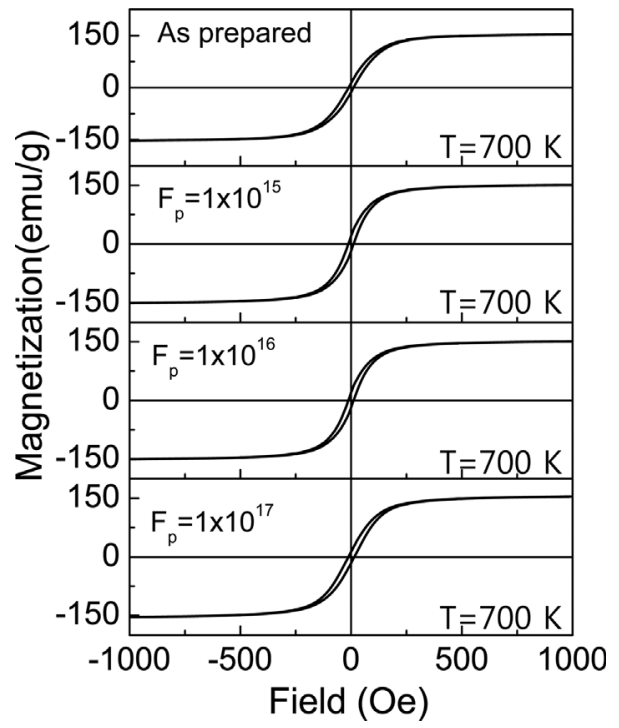

Fig. 4. Magnetic hysteresis loops of the stainless steel samples measured at $700 \mathrm{~K}$ after $3 \mathrm{MeV}$ proton irradiation with the doses ranging from $10^{15}-10^{17} \mathrm{p} / \mathrm{cm}^{2}$.

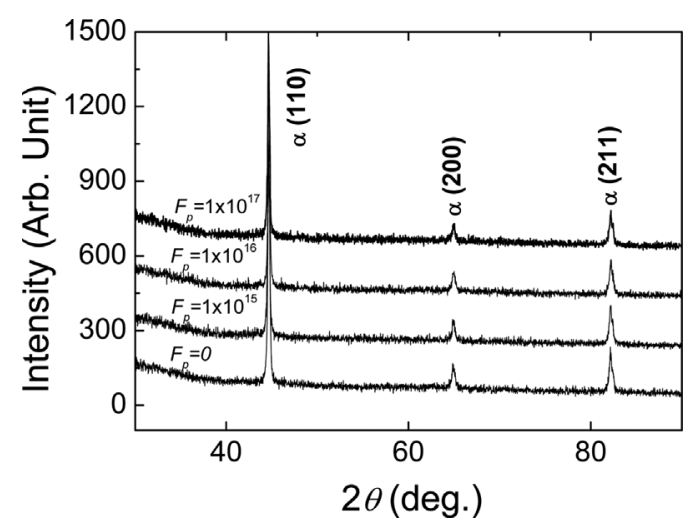

Fig. 5. XRD patterns of the stainless steel samples before and after $3 \mathrm{MeV}$ proton irradiation with the doses ranging from $10^{15}-10^{17} \mathrm{p} / \mathrm{cm}^{2}$.

have a close relationship with their structural properties. Therefore, structural properties of 410 stainless steels by varying the proton irradiation were also investigated using XRD measurements. The XRD patterns of the irradiated samples are presented in Fig. 5. As shown in Fig. 5, all the patterns are mainly composed of typical martensitic $(\alpha)$ phases. Equivalent XRD patterns can be observed for different irradiation fluence, which implies that the effect of proton irradiation on the structural properties of stainless steels is negligible. It also suggests that the 410 martensitic stainless steels have the proton radiation resistance up to $10^{17} \mathrm{p} / \mathrm{cm}^{2}$. It is worthwhile to mention that the neutron radiation resistance of martensitic stainless steels can be calculated from the observed proton re- 
sistance. The calculated dpa $\left(5.2 \times 10^{-3}\right.$ dpa for $F_{p}=$ $1 \times 10^{17} \mathrm{p} / \mathrm{cm}^{2}$ ) can be converted to neutron fluence using a representative displacement cross section $\left(1.5 \times 10^{-21}\right.$ dpa $\times \mathrm{cm}^{2} / \mathrm{n}, \mathrm{E}>1.0 \mathrm{MeV}$ ), which is a typical value for research reactor [13]. The corresponding neutron fluence was calculated to $3.5 \times 10^{18} \mathrm{n} / \mathrm{cm}^{2}$, which implies that magnetic and structural properties of 410 stainless steels have neutron resistance up to $3.5 \times 10^{18} \mathrm{n} / \mathrm{cm}^{2}$.

\section{Conclusion}

We investigated proton radiation resistance of 410 stainless steels by measuring the magnetic and structural properties using VSM and XRD. The $35 \mu \mathrm{m}$ thick samples of 410 stainless steels were exposed to the proton beam of $3 \mathrm{MeV}$ with the fluence ranging $10^{15}-10^{17} \mathrm{p} / \mathrm{cm}^{2}$. Significant changes of magnetic properties and structural properties due to the proton irradiation up to $10^{17} \mathrm{p} / \mathrm{cm}^{2}$ were not observed. This suggests that the 410 stainless steels have the radiation resistance up to $5.2 \times 10^{-3} \mathrm{dpa}$ which corresponds to neutron irradiation of $3.5 \times 10^{18} \mathrm{n} / \mathrm{cm}^{2}$. These results could be used to predict the maintenance period of SUS410 stainless steels in fission power plants.

\section{Acknowledgements}

This work was supported by the Nuclear Power Core Technology Development Program of the Korea Institute of Energy Technology Evaluation and Planning (KETEP), granted financial resource from the Ministry of Trade, Industry \& Energy, Republic of Korea (No. 20131510101680). This work was also supported by National Research Foundation of Korea (NRF-2013R1A2A2A01067144, NRF-2013R1A4A1069528).

\section{References}

[1] R. J. Kurtz, A. Alamo, E. Lucon, Q. Huang, S. Jitsukawa, A. Kimura, R. L. Klueh, G. R. Odette, C. Petersen, M. A. Sokolov, P. Spätig, and J.-W. Rensman, J. Nucl. Mater. 386, 411 (2009).

[2] K. Yin, S. Qiu, R. Tang, Q. Zhang, and L. Zhang, J. Supercrit. Fluids 50, 235 (2009).

[3] D. Squarer, T. Schulenberg, D. Struwe, Y. Oka, D. Bittermann, N. Aksan, C. Maraczy, R. Kyrki-Rajamäki, A. Souyri, and P. Dumaz, Nucl. Eng. Des. 221, 167 (2003).

[4] A. B. C, Yann de Carlan, Xavier Averty, Jean-Chrisophe Brachet, Jean-Luc Bertin, Frank Rozenblum, and Olivier Rabouille, J. ASTM Int. 2, JAI12354 (2005).

[5] Y. Z. Shen, S. H. Kim, H. D. Cho, C. H. Han, and W. S. Ryu, Nucl. Eng. Des. 239, 648 (2009).

[6] M. Noh, M. J. Gi, D. Kim, Y.-W. Park, J. Lee, and J. Kim, J. Magn. 20, 86 (2015).

[7] T. Ishida, S. Imayoshi, T. Yoritsune, H. Nunokawa, M. Ochiai, and Y. Ishizaka, J. Nucl. Sci. Technol. 38, 557 (2001).

[8] R. Schaeublin, D. Gelles, and M. Victoria, J. Nucl. Mater. 307, 197 (2002).

[9] S. Kim, S. Lee, J. Ko, J. Son, M. Kim, S. Kang, and J. Hong, Nature Nanotech. 7, 567 (2012).

[10] S. Kim, S. Lee, and J. Hong, ACS Nano 8, 4698 (2014).

[11] K. Yabuuchi, Y. Kuribayashi, S. Nogami, R. Kasada, and A. Hasegawa, J. Nucl. Mater. 446, 142 (2014).

[12] X. H. Li, J. Lei, G. G. Shu, and Q. M. Wan, Nucl. Instruments Methods Phys. Res. Sect. B 350, 14 (2015).

[13] R. E. Stoller, Effects of Radiation on Materials: 21st International Symposium, ASTM STP 1447, M. L. Grossbeck, T. R. Allen, R. G. Lott, and A. S. Kumar, Eds., ASTM International, West Conshohocken, PA (2003). 